\title{
The erosion of ambiguity tolerance and sustainment of perfectionism in undergraduate medical training: results from multiple samplings of a single cohort
}

\author{
Silvio Ndoja ${ }^{1 *}$ (D), Saad Chahine ${ }^{2}$, Donald H. Saklofske ${ }^{3}$ and Brent Lanting ${ }^{1,4}$
}

\begin{abstract}
Background: Medicine is a field that is simultaneously factual and ambiguous. Medical students have their first exposure to full time clinical practice during clerkship. While studies have examined medical trainees' tolerance of ambiguity (TOA), the extent to which TOA is affected by clinical experiences and its association with perfectionism is unknown. The aim of this study was to evaluate the effect of clerkship experience on TOA and perfectionism in medical students.

Methods: This was a multiple sampling, single cohort study of students in their first year of clinical clerkship which is comprised of 6 core rotations. Consenting students completed an online anonymous survey assessing their tolerance of ambiguity (TOA) and perfectionism in their first (pre) and last (post) 12 weeks of their clinical clerkship year. Tolerance of Ambiguity in Medical Students and Doctors (TAMSAD) and The Big Three perfectionism scaleshort form (BTPS-SF) were used to assess TOA and perfectionism respectively. Pre-Post mean comparisons of TOA and perfectionism were assessed via t-tests.

Results: From a cohort of 174 clinical clerkship students, 51 students responded to pre-survey, 62 responded to post-survey. Clerkship was associated with a significant decrease in TOA $(p<0.00)$ with mean pre-TOA scores of 59.57 and post TOA of 43.8. Perfectionism scores were not significantly different over time $(p>0.05)$. There was a moderate inverse correlation between TOA and perfectionism before clerkship $(r=0.32)$ that increased slightly after clerkship $(r=0.39)$. Those preferring primary care specialties had significantly lower rigid and total perfectionism scores in pre-clerkship than those choosing other specialties, but this difference was not found post-clerkship.

Conclusion: Exposure to clerkship decreased TOA while perfectionism remained stable in medical students. These results were not expected as exposure has been previously shown to increase TOA. The frequency of rotation changes maintaining a cycle of anxiety may be an underlying factor accounting for these results. Overall these results require further investigation to better characterize the role of clinical exposure on TOA.
\end{abstract}

Keywords: Tolerance of ambiguity, Perfectionism, Clerkship, Medical students

\footnotetext{
*Correspondence: silviondoja@gmail.com

'Schulich School of Medicine \& Dentistry, University of Western Ontario, 1151 Richmond St, London, ON N6A 5C1, Canada

Full list of author information is available at the end of the article
}

C C The Author(s). 2020 Open Access This article is licensed under a Creative Commons Attribution 4.0 International License, which permits use, sharing, adaptation, distribution and reproduction in any medium or format, as long as you give appropriate credit to the original author(s) and the source, provide a link to the Creative Commons licence, and indicate if changes were made. The images or other third party material in this article are included in the article's Creative Commons licence, unless indicated otherwise in a credit line to the material. If material is not included in the article's Creative Commons licence and your intended use is not permitted by statutory regulation or exceeds the permitted use, you will need to obtain permission directly from the copyright holder. To view a copy of this licence, visit http://creativecommons.org/licenses/by/4.0/ The Creative Commons Public Domain Dedication waiver (http://creativecommons.org/publicdomain/zero/1.0/) applies to the data made available in this article, unless otherwise stated in a credit line to the data. 


\section{Background}

Becoming a practicing physician requires the completion of an intensive and demanding residency program. In the final years of medical school, students must choose which of the 30 direct entry specialties they wish to specialize in as a career. Many factors can influence a student's choice in career paths including lifestyle, location, and "fit" $[1,2]$. The final years of medical school, also known as the clerkship years, are typically comprised of medical students getting first-hand experience in various medical fields. This serves a two-fold purpose: to create a comprehensive foundation of medical knowledge and to expose them to possible specialization career choices.

Each specialty can vary in the degree of patient information available to practitioners. Patients can present with vague, non-specific symptoms, such as diffuse abdominal pain, or exhibit clear presentations such as a fracture of the humerus due to a fall-or anywhere in between that spectrum. Different presentations are associated with different degrees of ambiguity in diagnoss, treatments, and prognosis. As such, different medical specializations and contexts may potentially be better suited to certain personality traits. Both tolerance of ambiguity and perfectionism are personality traits that vary across all persons, but not frequently researched in the context of medical education and thus are the focus of this study [3-5].

Tolerance of ambiguity (TOA) refers to how we perceive, respond to, and tolerate information that may lack credibility, and is uncertain [6-9]. While interest in TOA in the medical field can be traced back to the early 1990s, studies have often led to conflicting results, with some showing a larger, but non-statistically significant, TOA in 3rd-year medical students (first year of clerkship experience in North American schools) [6] and others showing no difference [10]. However, a recent review of 11 studies (Hancock and Mattick, 2020) concluded there was an association between a lower level of tolerance of ambiguity and lower psychological well-being amongst medical students and practicing doctors [3]. Residents have been reported to have higher TOA compared to medical students [11]. When examining baseline data of 13,867 matriculating first-year medical students in the United States in 2013, higher TOA was seen in men and older individuals [12]. Interestingly, there was a statistically significant relation between TOA and declared specialty of interest; those students pursuing specializations in Dermatology, Physical medicine, and rehabilitation, and otolaryngology have the lowest mean TOA scores in contrast to those selecting Psychiatry, Radiation Oncology, Emergency medicine, and Neurosurgery the highest TOA [13]. However, this was an incidental finding and no further analyses were done. Other studies have shown that surgeons have a lower TOA than other physicians [14]. However, we are not aware of research investigating how TOA changes with clinical exposure.

Perfectionism is a personality trait of interest in the medical field as it has been implicated in anxiety [15, 16], depression [17], and burnout [18-20]. While perfectionism may appear to have an intuitive definition, it is emerging to be a multi-dimensional construct. Although there are several models describing the composition of perfectionism, recent research has identified three measurable dimensions: rigid perfectionism, self-critical perfectionism, and narcissistic perfectionism [21]. Rigid perfectionism is defined as requiring "flawless performance from the self" [22], self-critical perfectionism is defined as negative responses to flawed performances [23], and narcissistic perfectionism refers to expecting perfectionism from others in a grandiose, hypercritical, and entitled way [24]. Medical students have been shown to have higher perfectionism scores than arts students, with maladaptive perfectionism being predictive of depression and academic distress [25], a result that has been replicated in other studies [18, 26, 27].

More recently, Leung et al. (2019) described a personality profile of medical students linking TOA and high levels of maladaptive perfectionism, which in turn may underlie vulnerability to stress and ineffective coping [4]. However, we are not aware of any studies investing how perfectionism may change with clinical training and experience and its relationship with TOA.

The aim of this study was guided by three research questions: 1) To what extent does relationship exist between TOA and perfectionism for medical students in their first year of clerkship? 2) How does clerkship modify these factors and/or their relationship? 3) Are perfectionism and TOA related to a student's specialty choice?

\section{Method \\ Participants and setting}

All medical students in their clerkship year at our local institution during the period August 27th, 2018 to August 9th, 2019 were invited to participate in an anonymous survey assessing these personality traits. Clerkship at our instution occurs during the 3rd year of medical school and is comprised of 6 broad specialties with opportunities of subspecialty exposures where applicable [28]. The Qualtrics ${ }^{\mathrm{TM}}$ online survey was comprised of questions requesting demographics information (gender and age), the TAMSAD and BTPS-SF questionaires, and a list of all medical specialties where students were asked to rank their preferred top 5 specialties. The survey was distributed to eligible applicants through the school's undergraduate medical education (UME) office, again with the participant's being anonymous to comply with UME policies. This was a repeated 
single cohort pre and post-study. The survey was distributed at 2 times points: the start of the first rotation (preclerkship) and again at the start of the last rotation (post-clerkship). Participants were required to complete all questions in the survey. At each distribution, students who had not completed the survey received a 2-week reminder. Students were offered token of appreciation of $\$ 5$ electronic gift card for each survey they completed for a total of $\$ 10$.

\section{Measures}

The Tolerance of Ambiguity in Medical Students and Doctors (TAMSAD), developed by Hancock, et al. (2015), is a 29 item Likert scale that specifically assess ambiguity in clinical situations [11]. This scale has good internal reliability and its use of clinical scenarios makes it an appealing tool for this study.

The 16 item Big Three Perfectionism Scale-Short Form (BTPS-SF; Feher, Smith, and Saklofske, 2019) assesses three broad factors: rigid perfectionism, selfcritical perfectionism, and narcissistic perfectionism [29]. The short form has demonstrated good internal consistency and retest reliability. Confirmatory factor analysis supports the three factor structure of the wellvalidated 45 item scale [24]. The short form was chosen for its ease of use and sound psychometric properties.

\section{Data analysis}

To ensure the anonymity of participants, it was not possible to match the participants' responses on the two administrations. Thus, data analyses were limited to descriptive statistics and group comparisons rather than comparisons of medical students across time. As well, the anonymous nature of data collection did not allow us to determine number of participants lost to follow up or new participants who later opted into the study. Data were analyzed with SPSS and pre- and post-test groups were compared using t-tests [30].

The relationship between TOA and perfectionism with specialty choice was assessed by grouping the top 3 specialties. This was done because of the lower than anticipated response rate, but also because family medicine, internal, and emergency medicine can be classified as primary care specialties. This combined group was compared to other remaining specialties. The pre and post surveys were analyzed separately.

\section{Results}

Of the total cohort of 174 students, 51 completed the pre- and 62 completed post-clerkship surveys that were retained for analysis. The gender split was somewhat comparable at time $1(\mathrm{~m}=24, \mathrm{f}=27)$ and time $2(\mathrm{~m}=$ $28, \mathrm{f}=34)$. The difference in participant ages at time 1 $(\mathrm{m}=25.31$ years, s.d. $=2.18)$ and time $2(\mathrm{~m}=26.00$ years, s.d. $=2.02$ ) was about $2 / 3$ rd of a year.

Overall specialty preferences remained stable in the pre and post surveys (Table 1). Family medicine, Internal medicine, Emergency medicine, Anesthesiology, and Pediatrics remained the top 5 most popular specialties from the start and end of clerkship. Family medicine remained the top with 15/51 ranking it first in the presurvey and 15/63 in the post-survey.

There was a statistically significant inverse correlation between perfectionism and TOA at time $1(-0.32, p<0.05)$ (Table 2). This result was maintained in the postsurvey $(-39, p<0.01)$. Of interest was that narcissitic and rigid perfectionism were significantly correlated with TOA only at the post survey data collection, whereas self-critical perfectionism showed a nonsignificant correlation with ambiguity tolerance at both times.

Of particular interest was the observed significant decrease in TOA between the pre and in the post-surveys $(p<0.01)$. Perfectionism levels remained stable $(p>0.05)$ for both the total and factor scores (Table 3). The scales showed excellent reliability with Cronbach's alpha consistently above 0.7 (Table 4 ).

For the pre survey, there was a significant difference between primary care and "other" group regarding rigid perfectionism $(p=0.01)$ and total perfectionism $(p=$ 0.01 ) (Table 5) with the primary care specialties having lower perfectionism scores. This relationship was not found in the post-survey $(p>0.05)$ (Table 6). There was a non significant relationship between specialties and self-critical perfectionism, narcissistic perfectionism, and TOA $(p>0.05)$. Of note was the decrease in self reported TOA for both groups over the period of the 1 year clerkship.

\section{Discussion}

The literature is scarce on perfectionism and TOA of medical students and the effect of clinical experience. This study adds to this growing body of literature and hopefully encourages further investigation of how clinical experiences and personality traits impact medical students' speciality choices and future performance as a

Table 1 Top 5 most popular specialties pre-clerkship where $n=$ 51, and post-clerkship where $n=63$ (post-clerkship response in brackets)

\begin{tabular}{llllll}
\hline Specialty & Rank $\mathbf{1}$ & Rank $\mathbf{2}$ & Rank $\mathbf{3}$ & Rank $\mathbf{4}$ & Rank 5 \\
\hline Family Medicine & $15(15)$ & $13(15)$ & $4(3)$ & $6(1)$ & $5(3)$ \\
Internal Medicine & $8(5)$ & $4(5)$ & $9(7)$ & $6(5)$ & $5(5)$ \\
Emergency Medicine & $5(3)$ & $7(12)$ & $7(3)$ & $8(9)$ & $4(2)$ \\
Anesthesiology & $2(1)$ & $3(2)$ & $5(5)$ & $5(5)$ & $3(2)$ \\
Pediatrics & $4(6)$ & $6(0)$ & $0(5)$ & $3(3)$ & $2(3)$ \\
\hline
\end{tabular}


Table 2 Relationship between perfectionism and TOA preclerkship and post-clerkship (post-clerkship relationship in brackets)

\begin{tabular}{lllll}
\hline & Rigid $^{\mathbf{a}}$ & SelfCrit $^{\text {b }}$ & Narcis $^{\mathbf{c}}$ & PerfTOT $^{\mathbf{d}}$ \\
\hline Rigid $^{\text {a }}$ & & & & \\
SelfCrit $^{\mathrm{b}}$ & $.56^{f}\left(.48^{f}\right)$ & & & \\
Narcis $^{\mathrm{c}}$ & $-.01(.20)$ & $.20(.09)$ & & \\
PerfTOT $^{\mathrm{d}}$ & $.75^{f}\left(.77^{f}\right)$ & $.89^{f}\left(.79^{f}\right)$ & $.48^{f}\left(.57^{f}\right)$ & \\
TOA $^{\mathrm{e}}$ & $-.24\left(-.42^{f}\right)$ & $-.24(-.18)$ & $-.25\left(-.26^{\mathrm{g}}\right)$ & $-.32^{\mathrm{g}}\left(.39^{f}\right)$ \\
\hline
\end{tabular}

${ }^{a}$ Self-critical perfectionism,

${ }^{\mathrm{b}}$ Rigid perfectionism

'Narcistic perfectionism,

${ }^{\mathrm{d}}$ Total perfectionism

e Tolerance of ambiguity

${ }^{f}$ Correlation is significant at the 0.01 level (2-tailed)

${ }^{g}$ Correlation is significant at the 0.05 level (2-tailed)

physician. Within the limitations of this study, there were some indications that students in this yearlong clinical exposure showed a decrease in their self reported tolerance of ambiguity (TOA) while perfectionism scores remained relatively stable. The perfectionism results were expected given that perfectionism is a relatively stable construct in adults [31]. In contrast, these TOA results were unexpected in relation to previous studies that reported an increase in TOA when participants are exposed to artificially ambiguous scenarios [32]. Cross sectional studies have shown final year medical students have similar TOA compared to those entering clerkship for their first year, and residents reporting higher TOA than medical students [11]. As such, clinical exposure decreasing TOA was an unexpected result. These findings might be indicative of the medical student's first year of clinical experience where "real" decisions about patients are required in contrast to classroom discussions; however further research is needed to confirm these current results. Previous studies have shown that intolerance of ambiguity (low TOA) has been implicated in anxiety [33]. Should these results hold, a possible area of inquiry might focus on the anxiety cycle.
Table 4 Cronbach's alpha for each variable used in the assessments

\begin{tabular}{lll}
\hline & Pre clerkship & Post Clerkship \\
\hline SelfCrit $^{\mathrm{a}}$ & 0.829 & 0.858 \\
Rigid $^{\mathrm{C}}$ & 0.826 & 0.84 \\
Narcis $^{\mathrm{c}}$ & 0.738 & 0.796 \\
PerfTOT $^{\mathrm{d}}$ & 0.832 & 0.837 \\
TOA $^{\mathrm{e}}$ & 0.757 & 0.701 \\
\hline
\end{tabular}

a Self-critical perfectionism,

${ }^{\mathrm{b}}$ Rigid perfectionism

' Narcistic perfectionism,

${ }^{\mathrm{d}}$ Total perfectionism

e Tolerance of ambiguity

Anxiety has been described to be maintained through short exposures and avoidance of anxiety inducing situations. Theortically, avoidance allows short term relief, and the short exposures do not allow for applying effective coping skills, which leads to worsening anxiety [34, 35]. Perhaps the decrease in TOA observed at the end of the year long clinical exposure may reflect this anxiety cycle in the medical training context. The frequency of rotation changes may be sensitizing students to ambiguity. At this institution, most rotations last approximately 2 weeks, with the longest lasting 6 weeks. As such, clinical clerks are shifted to different environments more frequently than residents who have rotations lasting months. The frequent changes may not allow medical students to get accustomed to the environment and develop the knowledge and skills to handle varied patient issues, which may leave them in a heightened state of discomfort. It is possible that in other studies, residents may have experienced a longer time span within and between rotations, and as such had more time to become accustomed to the uncertainty and develop coping strategies which would account for increased TOA.

This study demonstrated that those with lower rigid perfectionism were more likely to prefer primary care specialties at the beginning of clerkship. One hypothesis

Table 3 Pre and post-clerkship TOA and perfectionism

\begin{tabular}{|c|c|c|c|c|c|c|c|c|c|}
\hline & \multicolumn{2}{|c|}{ Pre Clerkship $(n=51)$} & \multicolumn{2}{|c|}{ Post Clerkship $(n=62)$} & \multirow[b]{2}{*}{ t-value } & \multirow[b]{2}{*}{ Df } & \multirow[b]{2}{*}{$p$-value } & \multirow[b]{2}{*}{$95 \% \mathrm{Cl}$} & \\
\hline & Mean & s.d & Mean & s.d. & & & & & \\
\hline SelfCrit ${ }^{a}$ & 3.22 & 0.91 & 3.24 & 0.86 & 0.12 & 111 & 0.91 & -0.31 & 0.35 \\
\hline Rigid $^{b}$ & 3.24 & 0.97 & 3.12 & 0.99 & 0.62 & 111 & 0.54 & -0.48 & 0.25 \\
\hline Narcis $^{c}$ & 1.79 & 0.59 & 1.81 & 0.68 & 0.15 & 111 & 0.88 & -0.22 & 0.26 \\
\hline PerfTOT $^{d}$ & 2.69 & 0.59 & 2.67 & 0.59 & 0.13 & 111 & 0.90 & -0.24 & 0.21 \\
\hline $\mathrm{TOA}^{\mathrm{e}}$ & 59.47 & 8.26 & 43.90 & 7.61 & 10.41 & 111 & 0.00 & -18.53 & -12.58 \\
\hline
\end{tabular}

s.d. Standard deviation, Df Degrees of freedom, $\mathrm{Cl}$ Confidence interval

a Rigid perfectionism,

b Self-critical perfectionism,

c Narcistic perfectionism,

${ }^{\mathrm{d}}$ Total perfectionism

e Tolerance of ambiguity 
Table 5 Relationship between specialty choices and TOA and perfectionism pre-clerkship

\begin{tabular}{|c|c|c|c|c|c|c|c|c|c|}
\hline & Primar & 28) & Other & & & & & & \\
\hline & Mean & s.d. & Mean & s.d. & $t$-value & df & $p$-value & $95 \% \mathrm{Cl}$ & \\
\hline SelfCrit ${ }^{a}$ & 3.08 & 0.75 & 3.40 & 1.06 & 1.27 & 49 & 0.21 & -0.83 & 0.19 \\
\hline Rigid $^{b}$ & 2.91 & 0.98 & 3.63 & 0.82 & 2.80 & 49 & 0.01 & -1.24 & -0.20 \\
\hline Narcis $^{c}$ & 1.65 & 0.55 & 1.96 & 0.61 & 1.86 & 49 & 0.07 & -0.63 & 0.02 \\
\hline PerfTOT ${ }^{d}$ & 2.50 & 0.54 & 2.92 & 0.59 & -2.62 & 49 & 0.01 & -0.73 & -0.10 \\
\hline$T O A^{e}$ & 60.04 & 9.34 & 58.77 & 6.86 & 0.54 & 49 & 0.59 & -3.44 & 5.97 \\
\hline
\end{tabular}

s.d. Standard deviation, Df Degrees of freedom, $\mathrm{Cl}$ Confidence interval

a Self-critical perfectionism,

${ }^{\mathrm{b}}$ Rigid perfectionism

' Narcistic perfectionism

${ }^{\mathrm{d}}$ Total perfectionism

e Tolerance of ambiguity

is that rigid perfectionism, which is defined as "our own performance must be perfect", is appropriately low in those preferring primary care specialties [21]. Primary care specialties are often filled uncertain outcomes, which largely depend on patient compliance to treatment regiments [36, 37]. A physician's performance in these situations does not have the same impact on patient outcomes and other areas of medical practice. Patient compliance has been shown to be influenced by factors such as a providers' empathy, in contrast to their medical knowledge [38, 39]. As such, those thriving in primary care must be flexible in their approaches to patient care which is conducive to those with low rigid perfectionism.

\section{Study strength}

The key strength of this study is its repeated sampling of a single cohort at the start and end of their first year of clinical experiences. The two samplings allow a deeper insight into how these factors can change with time and impact the variability experienced in medical training. Previous research has studied differences in ambiguity across levels of medical training through a cross-sectional design which limits their generalizability $[11,12]$.

\section{Limitations}

While these findings present some interesting preliminary considerations, there are several limitations. While there were two data collection periods with a single cohort, due to the nature of this survey, it was not possible to match participants at the two time points. This limits the extent to which one can infer the effect of clinical exposure on the same persons over time, compared to other confounders which were not controlled for. Another limitation is the variety of clinical exposures. While all students had similar broad specialty exposures, there are variations in the encounters they may have had within a specialty, or in the subspecialty exposures. The anonymous nature of the study hindered capturing such granular data. While individual person level between pre and post assessment could not be matched, there was a substantial overlap between those who took this survey at the start of clerkship and those who completed it at the end of clerkship. With regards to student participation, 50 students responded to the pre-survey and 62 the post-survey. This represents a response rate of 29 and

Table 6 Relationship between specialty choices and TOA and perfectionism post-clerkship

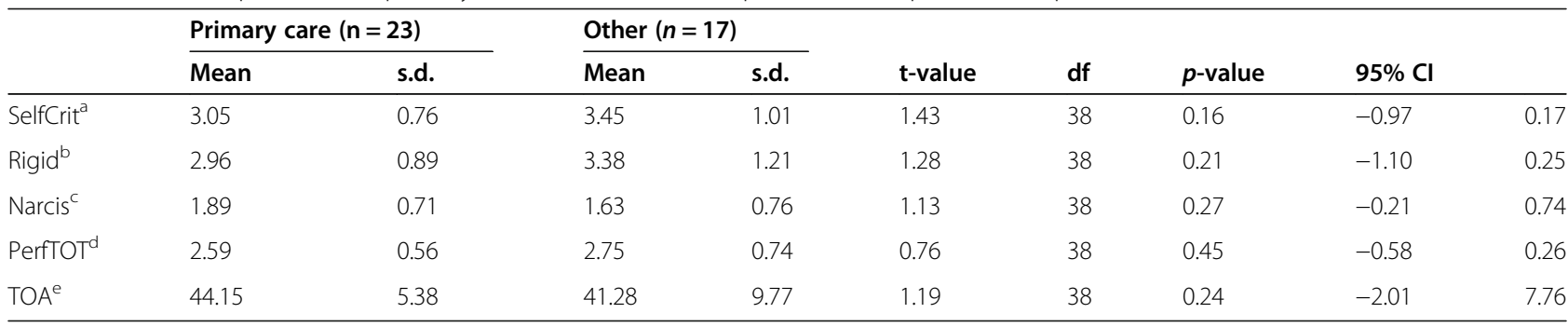

s.d. Standard deviation, Df Degrees of freedom, Cl Confidence interval

a Self-critical perfectionism,

${ }^{\mathrm{b}}$ Rigid perfectionism

c Narcistic perfectionism,

dTotal perfectionism

e Tolerance of ambiguity 
$35 \%$ respectively of the larger cohort of students which limits the extent to which the findings can be generalized to this group, even though participation was around $30 \%$ which is in keeping with reported response rates of web-based surveys in the medical field [40].

\section{Conclusions}

This study demonstrates a decrease in TOA with clinical experience. This was an unexpected finding and not previously found in the literature. One hypothesis for this finding may be due to a sensitization phenomenon. With regards to specialty choices, at the beginning of clerkship, those who ranked primary care specialties as their most preferred choice reported lower levels of perfectionism, specifically rigid perfectionism. Further research in this field is necessary in order to better understand the impact of these personality traits in the clinical field.

\section{Abbreviations}

TOA: Tolerance of ambiguity; SelfCrit: Self-critical perfectionism;

Narcis: Narcissistic perfectionism; TAMSAD: Tolerance of Ambiguity in Medical Students and Doctors

\section{Acknowledgements}

We would like to acknowledge the Undergraduate Medical Education office for facilitating the distribution of this study.

\section{Authors' contributions}

SN contributed to study design, participant recruitement, and manuscript preparation. SC contributed to study design, data analysis, and manuscript preparation. DS contributed to study design, and manuscript preparation. BL contributed to study design, and manuscript preparation. The authors have read and approved the manuscript.

\section{Funding}

This project was funded through the Arthroplasty research fund. Funding was used to pay for gift card insentives as outlined in the methods section. The senior author, BL, is a member of the Divsion of Arthroplasty. BL was involved in study design and manuscript preparation.

\section{Availability of data and materials}

The datasets used and/or analyzed during the current study are available from the corresponding author on reasonable request.

\section{Ethics approval and consent to participate}

Ethics approval and consent to participate was obtained through Western University Health Science Research Ethics Board (HSREB) and Lawson Health Research institute for human participants.

HREB Application Number 112320 and Lawson application number: R-18-522. Lawson approval was obtained August 8th 2018 and HREB on August 22nd 2018.

\section{Consent for publication}

Not applicable.

\section{Competing interests}

One of the co-authors (SN) was a member of the studied cohort. As such, there may be a conflict of interest in the recruitment process and results. To minimize this conflict, the survey was distributed by the school, and not a member of the team. SN did not participate in the survey. Data was analyzed by another member of the team (SC) who is a researcher and does not have clinical responsibilities, and therefore has no exposure to members of the studied cohort. BL is a staff orthopaedic surgeon who may have interacted with students studied in this cohort. BL participated in study design and manuscript preparation, but was not involved in data analysis or recruitment.

\section{Author details}

${ }^{1}$ Schulich School of Medicine \& Dentistry, University of Western Ontario, 1151 Richmond St, London, ON N6A 5C1, Canada. ${ }^{2}$ Faculty of Education, Queen's University, Duncan McArthur Hall, 511 Union St W, Kingston, ON K7M 5R7, Canada. ${ }^{3}$ Department of Psychology, University of Western Ontario, 1151 Richmond St, London, ON N6A 5C1, Canada. ${ }^{4}$ London Health Sciences, 339 Windermere Rd, London, ON N6A 5A5, Canada.

Received: 19 January 2020 Accepted: 30 October 2020

Published online: 10 November 2020

\section{References}

1. Dorsey ER, Jarjoura D, Rutecki GW. Influence of controllable lifestyle on recent trends in specialty choice by US medical students. JAMA. 2003; 290(9):1173-8.

2. Dorsey ER, Jarjoura D, Rutecki GW. The influence of controllable lifestyle and sex on the specialty choices of graduating U.S. medical students, 1996-2003. Acad Med. 2005;80(9):791-6.

3. Hancock J, Mattick K. Tolerance of ambiguity and psychological well-being in medical training: a systematic review. Med Educ. 2020;54(2):125-37. https://doi.org/10.1111/medu.14031.

4. Leung J, Cloninger CR, Hong BA, Cloninger KM, Eley DS. Temperament and character profiles of medical students associated with tolerance of ambiguity and perfectionism. PeerJ. 2019;7:e7109.

5. Eley DS, Leung JK, Campbell N, Cloninger CR. Tolerance of ambiguity, perfectionism and resilience are associated with personality profiles of medical students oriented to rural practice. Med Teach. 2017;39(5): 512-9.

6. Budner S. Intolerance of ambiguity as a personality variable. J Pers. 1962; 30(1):29-50.

7. Furnham A, Marks J. Tolerance of ambiguity: a review of the recent literature. Psychology. 2013;04(09):717-28Available from: http://www.scirp. org/journal/doi.aspx? DOl=. https://doi.org/10.4236/psych.2013.49102.

8. Furnham A, Ribchester T. Tolerance of ambiguity: a review of the concept, its measurement and applications. Curr Psychol. 1995;14(3):179-99.

9. Hillen MA, Gutheil CM, Strout TD, Smets EMA, Han PKJ. Tolerance of uncertainty: conceptual analysis, integrative model, and implications for healthcare. Soc Sci Med. 2017;180:62-75.

10. Geller G, Faden RR, Levine DM. Tolerance for ambiguity among medical students: implications for their selection, training and practice. Soc Sci Med. 1990;31(5):619-24 Available from: http://linkinghub.elsevier.com/retrieve/pii/ 027795369090098D.

11. Hancock J, Roberts M, Monrouxe L, Mattick K. Medical student and junior doctors' tolerance of ambiguity: development of a new scale. Adv Health Sci Educ Theory Pract. 2015;20(1):113-30.

12. Caulfield M, Andolsek K, Grbic D, Roskovensky L. Ambiguity tolerance of students matriculating to U.S. medical schools. Acad Med. 2014;89(11): 1526-32.

13. McCulloch P, Kaul A, Wagstaff GF, Wheatcroft J. Tolerance of uncertainty, extroversion, neuroticism and attitudes to randomized controlled trials among surgeons and physicians. Br J Surg. 2005;92(10):1293-7.

14. Geller G, Tambor ES, Chase GA, Holtzman NA. Measuring physicians' tolerance for ambiguity and its relationship to their reported practices regarding genetic testing. Med Care. 1993;31(11):989-1001. https://www. jstor.org/stable/3766298?casa_token=DG6eBt12BfcAAAAA\%3 Ap0GZe99AyeNILvwJ7mFq0HRuJiYBMeEc8JPvxjSQY2N3 xhdRpdhhdKwaqldTCKOaQVNMDX5216qd6IPobLIEwKUG4zUhSmTUFf5 pGAqu4FXQsr21EBQa\&seq=1\#metadata_info_tab_conte.

15. Smith MM, Vidovic V, Sherry SB, Stewart SH, Saklofske DH. Are perfectionism dimensions risk factors for anxiety symptoms? A meta-analysis of 11 longitudinal studies. Anxiety Stress Coping. 2018;31 (1):4-20.

16. Kim C, Seockhoon C, Suyeon L, Soyoun Y, Boram P. Perfectionism is related with academic stress in medical student. Eur Psychiatry. 2017;41(S1):S690.

17. Seeliger $\mathrm{H}$, Harendza S. Is perfect good? - dimensions of perfectionism in newly admitted medical students. BMC Med Educ. 2017;17(1):206 Available from: https://bmcmededuc.biomedcentral.com/articles/10.1186/s12909-01 7-1034-9.

18. Craiovan PM. Correlations between perfectionism, stress, psychopathological symptoms and burnout in the medical field. Procedia-Social Behav Sci. 2014;127:529-33. 
19. Sibeoni J, Bellon-Champel L, Mousty A, Manolios E, Verneuil L, Revah-Levy A. Physicians' perspectives about burnout: a systematic review and metasynthesis. J Gen Intern Med. 2019;34(8):1578-90.

20. Cahan EM. Students Shouldn't merely 'Survive'Medical school. Health Aff. 2019:38(9):1585-8.

21. Smith MM, Saklofske DH, Stoeber J, Sherry SB. The Big three perfectionism scale: a new measure of perfectionism. J Psychoeduc Assess. 2016;34(7): 670-87.

22. Smith MM, Smith MM, Big T, Saklofske DH, Stoeber J, Sherry SB. The big three perfectionism scale: a new measure of perfectionism. J Psychoeduc Assess. 2016:34(7):670-87.

23. Dunkley DM, Zuroff DC, Blankstein KR. Self-critical perfectionism and daily affect: dispositional and situational influences on stress and coping. J Pers Soc Psychol. 2003;84(1):234.

24. Smith MM, Saklofske DH, Stoeber J, Sherry SB. The big three perfectionism scale: a new measure of perfectionism. J Psychoeduc Assess. 2016;34(7): 670-87.

25. Enns MW, Cox BJ, Sareen J, Freeman P. Adaptive and maladaptive perfectionism in medical students: a longitudinal investigation. Med Educ. 2001;35(11):1034-42

26. Yu JH, Chae SJ, Chang KH. The relationship among self-efficacy, perfectionism and academic burnout in medical school students. Korean $J$ Med Educ. 2016;28(1):49.

27. Bright RP, Krahn L. Depression and suicide among physicians. Curr Psychiatr Ther. 2011;10(4):16.

28. Undergraduate Medical Education. Statement 3.2.24 - summary of clerkship rotations. Schulich School Med Dent. 2013; [cited 2020 Aug 1]. Available from: https://www.schulich.uwo.ca/medicine/undergraduate/docs/policies statements/statements/3-2-24-Statement-on-Summary-of-ClerkshipRotations.pdf.

29. Feher A, Smith MM, Saklofske DH, Plouffe RA, Wilson CA, Sherry SB. The Big three perfectionism scale-short form (BTPS-SF): development of a brief selfreport measure of multidimensional perfectionism. J Psychoeduc Assess. 2020;38(1):37-52.

30. IBM. SPSS statistics for windows. New York: IBM Corp; 2017.

31. Rice KG, Richardson CME, Clark D. Perfectionism, procrastination, and psychological distress. J Couns Psychol. 2012:59(2):288.

32. Endres ML, Camp R, Milner M. Is ambiguity tolerance malleable? Experimental evidence with potential implications for future research. Front Psychol. 2015;6:619.

33. Carleton RN, Mulvogue MK, Thibodeau MA, McCabe RE, Antony MM Asmundson GJG. Increasingly certain about uncertainty: intolerance of uncertainty across anxiety and depression. J Anxiety Disord. 2012;26(3):468-79.

34. Hofmann SG. Cognitive processes during fear acquisition and extinction in animals and humans: implications for exposure therapy of anxiety disorders. Clin Psychol Rev. 2008;28(2):199-210.

35. Birbaumer N, Kimmel HD (Eds.). Biofeedback and Self-Regulation. Hillsdale NJ: Lawrence Erlbaum Associates; 1979. https://scholar.google.com/scholar_ lookup?title=Extensions\%20of\%20twofactor\%20theory\%3A\%20cognitive\%2 Oavoidance\%20and\%20autonomic\%20perception\&publication_year= 1979\&author=T.D.\%20Borkovec

36. Ugolini C, Bruni ML, Leucci AC, Fiorentini G, Berti E, Nobilio L, et al. Disease management in diabetes care: when involving GPs improves patient compliance and health outcomes. Health Policy (New York). 2019;123(10): 955-62.

37. Lieberman JA 3rd. Compliance issues in primary care. J Clin Psychiatry. 1996; $57: 76$

38. Kim SS, Kaplowitz S, Johnston MV. The effects of physician empathy on patient satisfaction and compliance. Eval Health Prof. 2004;27(3):237-51.

39. Falvo D, Woehlke P, Deichmann J. Relationship of physician behavior to patient compliance. Patient Couns Health Educ. 1980;2(4):185-8.

40. Cunningham CT, Quan H, Hemmelgarn B, Noseworthy T, Beck CA, Dixon E, et al. Exploring physician specialist response rates to web-based surveys. BMC Med Res Methodol. 2015;15(1):32.

\section{Publisher's Note}

Springer Nature remains neutral with regard to jurisdictional claims in published maps and institutional affiliations.

Ready to submit your research? Choose BMC and benefit from:

- fast, convenient online submission

- thorough peer review by experienced researchers in your field

- rapid publication on acceptance

- support for research data, including large and complex data types

- gold Open Access which fosters wider collaboration and increased citations

- maximum visibility for your research: over $100 \mathrm{M}$ website views per year

At BMC, research is always in progress.

Learn more biomedcentral.com/submissions 